\section{Programa Bolsa-Alimentação: objetivo e perspectivas}

\section{The Bolsa-Alimentação Program: objective and perspectives}

Ministério da Saúde. Secretaria de Políticas de Saúde. Coordenação Geral da Política de Alimentação e Nutrição 1

${ }^{1}$ Ministério da Saúde. Secretaria de Políticas de Saúde. Coordenação Geral da Política de Alimentação e Nutrição. SEPN 511, Edifício Bittar IV, Bloco C, $4^{\circ}$ andar. Esplanada dos Ministérios. Brasília, DF, Brasil. CEP: 70.750-543. Tel: (61) 448-8040 / 448-8234. Fax: (61) 448-8239. E-mail: bolsa.alimentacao@saude.gov. br

"A Alimentação e a Nutrição constituem requisitos básicos para a promoção e a proteção à saúde, possibilitando a afirmação plena do potencial de crescimento e desenvolvimento humano com qualidade de vida e cidadania."

(Atributos consignados na Declaração Universal dos Direitos Humanos)

A Política Nacional de Alimentação e Nutrição, reconhece a alimentação e a nutrição como direitos humanos fundamentais e foi aprovada pelo Conselho Nacional de Saúde em maio de 1999, tendo como propósito: "A garantia da qualidade dos alimentos colocados para o consumo no País, a promoção de práticas alimentares saudáveis e a prevenção e o controle dos distúrbios nutricionais. "1

São inúmeros os problemas inerentes à alimentação e à nutrição inadequadas cabendo destacar as informações oriundas do Fundo das Nações Unidas para a Infância (UNICEF) ${ }^{2}$ dando conta de que nos países em desenvolvimento, cerca de $55 \%$ das mortes infantis estão ligadas à desnutrição. Não existe na história recente da humanidade, apesar dos avanços alcançados na redução da prevalência deste problema, qualquer situação mórbida com esta magnitude. Além do efeito mais desfavorável - mortalidade - a desnutrição agrava o curso de outras doenças, prolonga o tempo de internação e resulta em seqüelas para o desenvolvimento mental.

Dados de 1996 obtidos pela Pesquisa Nacional de Demografia e Saúde indicam que os avanços brasileiros no combate à desnutrição têm sido substanciais. Em 1989, 15,7 \% das crianças brasileiras apresentavam déficit de altura. Em 1996 esta prevalência decaiu para $10,5 \%$ em termos médios, ou seja, uma redução expressiva de $33 \%$. No entanto, foram observadas variações significativas entre as regiões brasileiras: de $5,1 \%$ no Sul a $17,9 \%$ no Nordeste. 3

A situação também se mostrava favorável para o País quando analisado o indicador de déficit de peso para idade. De uma taxa, em 1989, de 7,2\% de cri- anças até cinco anos com pesos inferiores ao esperado, foi verificado, em 1996, um decréscimo para $5,7 \%$. Isso significou uma redução de $21 \%$, ou $2,9 \%$ ao ano. As maiores frequiências de crianças com pesos baixos foram registradas nas regiões Norte $(7,7 \%)$ e Nordeste $(8,3 \%)$. Nesta última o decréscimo verificado para o período entre 1989 e 1996 foi de $35,1 \%$, que representa um redução ainda maior do que a média nacional de cerca de $5 \%$ ao ano. ${ }^{4}$

No entanto, apesar dos avanços, um contingente considerável de crianças brasileiras ainda apresentava atraso no seu crescimento com concentração nas famílias de mais baixa renda e socialmente excluídas.

Nestas famílias, o quadro de morbimortalidade infantil é ainda dominado pelo binômio desnutrição/infecção, o que exige do Estado medidas que visem prover as condições para que tenham capacidade de adquirir sua própria alimentação e acesso às ações e serviços de saúde.

Com base nestas premissas, o Governo Federal lançou o Programa Bolsa-Alimentação em parceria com Estados e Municípios. Este Programa tem por objetivo combater a mortalidade infantil e a desnutrição nas famílias mais carentes do país. Seu público-alvo são crianças até 6 anos, gestantes e mães que estejam amamentando e espera-se atender 3,5 milhões de cidadãos (400 mil nutrizes, 400 mil gestantes e 2,7 milhões de crianças em risco nutricional) por ano. Cerca de $50 \%$ destas crianças e mulheres residem na região Nordeste. 


\section{Programa Bolsa-Alimentação}

O Programa Bolsa-Alimentação consiste na promoção de melhores condições de saúde e nutrição de gestantes, mães que amamentam seus filhos e crianças até seis anos, em risco nutricional, pertencentes a famílias sem renda ou que possuam renda mensal de até meio salário mínimo per capita. Atua em dois eixos: complementação da renda familiar para a me-lhoria da alimentação e fomento à realização de ações básicas de saúde com enfoque predominantemente preventivo.

Uma vez cadastrada no Programa, a família compromete-se a cumprir uma "Agenda de Compromissos" com a sua saúde que consiste em participar de ações básicas de saúde como o pré-natal, vacinação, acompanhamento do crescimento e desenvolvimento infantil e atividades educativas sobre saúde e nutrição. A família receberá o benefício financeiro em parcelas mensais por um período de seis meses, podendo renová-lo por iguais períodos mediante a avaliação do cumprimento da "Agenda de Compromissos" e a manutenção dos critérios sócioeconômicos de elegibilidade.

Cada beneficiário do Programa deve ser assistido por uma equipe de saúde da família, agentes comunitários de saúde ou uma unidade básica de saúde, que proverão os serviços necessários para o cumprimento da agenda.

O benefício financeiro do Programa Bolsa-Alimentação é de $\mathrm{R} \$ 15,00$ (quinze reais) a $\mathrm{R} \$ 45,00$ (quarenta e cinco reais) mensais por família, dependendo do seu tamanho e composição. Estima-se que a maior parte das famílias receberá os $\mathrm{R} \$ 45,00$. O benefício é pago por meio de cartão magnético e o saque poderá ser efetuado nas agências da Caixa Econômica Federal ou em seus correspondentes bancários.

O Programa Bolsa-Alimentação é destinado a todos os municípios brasileiros que estejam habilitados em alguma das condições de gestão estabelecidas pelo Sistema Único de Saúde (SUS). Cabe à Secretaria Municipal de Saúde a oferta das ações básicas de saúde para os participantes do Programa, bem como a seleção, inscrição e acompanhamento dessas famílias.

As Secretarias Estaduais de Saúde, além de seu importante papel na concepção do programa, devem coordenar, em nível estadual, a sua implantação, acompanhamento e avaliação. O Governo Federal está alocando $\mathrm{R} \$ 572.000 .000,00$ (quinhentos e setenta e dois milhões de reais) por ano para o Programa, provenientes do Fundo de Combate e Erradicação da Pobreza.
Para garantir a eficiência redistributiva do Programa foram alocados mais recursos para os municípios e regiões mais vulneráveis. Para tal o Ministério da Saúde adotou os percentuais de crianças em risco nutricional estimados para cada município brasileiro pelo Núcleo de Estudos e Pesquisas Epidemiológicas Nutricionais e de Saúde da Universidade de São Paulo (NUPENS, USP). A partir destes percentuais e das estimativas populacionais do Instituto Brasileiro de Geografia e Estatística Instituto Brasileiro de Geografia e Estatística (IBGE) foram definidos os números iniciais de bolsas para cada município.

O valor per capita estipulado em $\mathrm{R} \$ 15,00$ levou em conta análises de dados de pesquisas de orçamento familiar do IBGE, propostas de cestas básicas econômicas do Núcleo de Estudos e Pesquisas em Alimentação da Universidade Estadual de Campinas (NEPA, UNICAMP), preços médios dos alimentos básicos levantados pelo Departamento Intersindical de Estatística e Estudos Sócio-Econômicos (DIEESE) e estudos complementares da área técnica de alimentação e nutrição do Ministério da Saúde.

Dessa forma, um apoio de $\mathrm{R} \$ 15,00$ (quinze reais) permite a aquisição de alimentos que forneçam cerca de 50\% das necessidades calóricas e de nutrientes de crianças e mães. Sugestões de compras estão incluídas na Agenda entregue para todos os beneficiários.

As variações de preços e do poder de compra são elevadas entre as diferentes regiões do país, o que faz com que seja importante a avaliação efetiva e continuada do valor do benefício.

O Programa ainda incentiva o uso de alimentos produzidos localmente, principalmente aqueles que têm sido gradualmente excluídos dos nossos hábitos alimentares. Para tal, o Ministério da Saúde está produzindo um material complementar para que os agentes comunitários de saúde conheçam as frutas e verduras regionais e possam recomendá-las para a população.

O esquema de avaliação de resultados e impactos do Programa Bolsa-Alimentação está previsto desde a sua concepção e contempla a análise dos seus efeitos a curto, médio e longo prazos sobre a população participante, tanto na esfera individual, como na familiar e no contexto comunitário. Para a avaliação do Programa Bolsa-Alimentação serão utilizadas diversas metodologias que incluem instrumentos quantitativos e qualitativos, bem como estudos repetidos no tempo.

O Programa Bolsa-Alimentação conta, ainda, com processos internos de monitoramento que permitem os gestores do programa em nível municipal, estadual e federal detectar problemas em sua ope- 
ração e implementar medidas oportunas para sua solução.

As dimensões mais importantes a serem avaliadas são seus resultados e impactos diretos e indiretos, tais como: melhorar o crescimento das crianças e a qualidade da alimentação das famílias e aumentar o grau de informação das mães sobre alimentação saudável, a freqüência às ações básicas de saúde, a participação da mulher no gerenciamento dos recursos da família e o nível da atividade econômica local, principalmente sobre a produção e comercialização de produtos alimentares básicos.

O Programa Bolsa-Alimentação é uma ação conjunta de Municípios, Estados e Governo Federal para melhorar as condições nutricionais de crianças e gestantes e reduzir, até 2003 , a taxa de mortalidade infantil de 33,5 óbitos por mil nascidos vivos (índice verificado no ano 2000) para 30 por mil. Para o alcance desta meta cabe a cada parceiro, gestor do SUS, fazer a sua parte.

\section{Referências}

1. Ministério da Saúde. Secretaria de Políticas de Saúde. Departamento de Formulação de Políticas de Saúde. Política nacional de alimentação e nutrição. Brasília, DF: Ministério da Saúde; 2000

2. BEMFAM. Sociedade Civil Bem-Estar Familiar no Brasil, Macro International. Pesquisa nacional sobre demografia e saúde, 1996. Rio de Janeiro: BEMFAM, Macro Internacional; 1997.

3. UNICEF. Fundo da Nações Unidas para a Infância. Situação mundial da infância. Brasília, DF: UNICEF; 1998.

4. Ministério da Saúde. Coordenação Materno-Infantil. Metas da cúpula em favor da infância - Avaliação de meia década - 1990/1995. Brasília, DF: Ministério da Saúde; 1997 